\title{
The Application of Big Data Technology in Library Information Resource Construction
}

\author{
Xin Fu \\ Shandong Agriculture and Engineering University, Jinan City, Shandong Province, 250100, China
}

Keywords: Big data, Library, Information, Resource Construction

\begin{abstract}
The arrival of big data's era not only changes people's life, work and thinking mode, but also has a subtle influence on the development of university library to a great extent. With the rise and continuous development of big data, the construction and development of university library has also innovated the service mode under the influence of big data. Based on the author's learning and practical experience, this paper first analyzed the influence of big data on the construction of information resources in university libraries, and then put forward the corresponding strategies for the construction of information resources of university libraries in the era of big data.
\end{abstract}

\section{Introduction}

The so-called big data refers to that the scale of the resources involved are very large, and there is no way through the current software tools in the specified time to achieve effective extraction management and processing. In addition, it is the timely collation of information to help businesses in business decisions so that to provide favorable information. In 2015, the State Council issued the "Platform for Action for the Development of Big Data" in the text of "National Development report 2015(50)", which systematically expounded the situation and significance of the development and application of big data. It clarified the guiding ideology, goals and tasks of big data's development and application in China, and put forward the requirements, and perfected the safeguard mechanism at the national level. This is the guidance and development of China on the development and use of major data an important programmatic document. In today's competitive society, people who does not attach importance to and use big data will be in the passive position of competition and also will be eliminated by cruel competition.

\section{The influence of big data on the construction of information resources in university libraries}

\subsection{The influence on the construction idea of university library resources}

Big data is not only a kind of rich data generalization, but also an advanced technology. It is also a way of thinking to discover the essence of the development of things. Big data expert Schenberger in his book the Big Data Age: Life, Work and Thinking Big Change, pointed out that there are three major changes in the way people think of data in a big data age: The data people deal with are not random samples, but all data; because of all the data, people have to accept the confounding of the data, and give up the pursuit of accuracy; people's thinking of solving problems turns from the pursuit of causality into concern about the relationship. The construction of information resources refers to the whole process of people choosing, collecting, organizing and developing all kinds of media information in a disordered state, so as to form a system of information resources that can be used. The arrival of big data era has caused people to re-examine the value of data, and has also provided new ideas for the construction of information resources in university libraries. The transformation of big data's thinking requires that the university library, as the information resource center, pay more attention to the user's data and its information utilization behavior in the process of obtaining, storing, organizing and providing utilization of resources. Moreover, it also requires that focuses on mining data value, discovers potential needs of users from the perspective of data, and 
then carries out information resource construction and service according to the needs of users.

\subsection{The influence of university library resources purchase pattern}

In the construction of university library resources, according to the principles of literature collection and selection of the library and the development needs of the discipline and specialty of the university, it requires to search and screen the bibliographic information. It makes a reasonable judgment on whether the documents can meet the needs of the users, and selects the documents suitable for the library collection. Interviewers get information on user needs through the participation of academic experts and teachers in the selection of books, the recommendation of readers' books, and the online questionnaire survey. The quality of university library purchasing resources depends on the staff's experience and judgment to a great extent. With the application of big data technology and tools, the process of selecting, collecting and processing university library resources is transformed into a process supported by data analysis. It is helpful for university library to change the model of resource purchasing from personal experience model to data analysis model, which is helpful to set up the resource purchasing mode based on user's demand and improve the scientific and systematic information resources construction.

\subsection{The influence on the resource organization of university library}

Information resource organization is an important link in the construction of information resources in university library. Information resources must be effectively organized and integrated in order to be discovered and utilized by users. Traditional information resources organization way is network-based and semantic processing of resources through providing knowledge classification navigation, citation link, related document link, and establishing knowledge- related network. Through the development or introduction of resources discovery platform, integrated books, periodicals, network resources and other types of data, university libraries provide users with search and discovery services. Large data technology can provide a strong support for the dynamic construction of the knowledge system and the effective presentation of the retrieval results. Through big data technology, the library can synthetically use a variety of data sources to provide a variety of media forms and knowledge points for users to search and return the results of knowledge association. It greatly optimizes the search results of library resources, enhances the relevance of library information resources, and improves the possibility of library information resources discovery.

\subsection{The influence on the resource sharing of university library}

In recent years, university libraries at home and abroad are generally faced with the problems of tight resources construction funds and rising document prices. It is necessary to actively carry out inter-library cooperation, resources alliance procurement and cooperative collection development. In order to improve the level of use of funds, to achieve the sharing of resources. But how to balance the specific needs of various institutions and balance the needs of various disciplines and the cost of purchasing resources has been a difficult problem in the library community. The development of big data technology provides an effective support for the storage and processing of massive and heterogeneous data. relying on the large data technology, the university library alliance organization can integrate, process and share the data resources owned by different libraries, and can master the overall situation of the acquisition, utilization and demand of the user resources of the university library system in a more comprehensive and timely manner, so that to further optimize the resource allocation according to the actual needs of the libraries and improve the benefit of sharing the information resources.

\section{Countermeasures for the construction of information resources in university libraries in big data era}

\subsection{Comprehensive understanding of the connotation of information resources construction}

The construction of information resources is the whole process of selecting, collecting, 
organizing and developing the media information in various disordered states through human labor, so as to form the system of information resources which can be utilized. According to this definition, the connotation of information resources construction includes three elements: media information, science and technology and facilities, and human wisdom. The three are interrelated, interdependent and indispensable to each other. Only when these three constructions are implemented synchronously and synchronously promoted can the construction of information resources be satisfied with the readers.

\subsection{Establishment of information resource construction target system}

Based on the unrestrictive and changeable nature of readers' needs and the long-term contradiction with the limitation of college library collection and acquisition funds, the construction of information resources is a long-term work. Therefore, the construction of information resources in university libraries must define the construction objectives of different periods and stages. In the era of big data, the "four modernizations" of readers' demands for information resources should be taken as the construction target system. Only in accordance with the established target system step by step, can we ensure that the distance between the construction of information resources and the needs of readers can be narrowed step by step.

\subsection{Construct information resource structure system meeting needs of readers}

In order to construct the information resource structure system to meet the needs of readers, we must thoroughly change the traditional thinking and decision-making mode, and scientifically lead the construction of information resources with a brand new management mode. First of all, we should attach great importance to the extensive acquisition of information resources and the various behaviors of the readers to use information resources. Secondly, we need to use big data technology to deeply analyze readers' utilization, recognition, habits, interests, hobbies, development direction of existing information resources, so as to find out the law of invisibility. Moreover, we have to predict the reader's demand for information resources, demand direction, demand trends and so on; thirdly, we should formulate strategies, plan and implement programs according to the actual situation, and scientifically determine the priorities, scale and proportion of different types, levels, forms and contents of information resources. Fourth, according to the funding situation, we should make great efforts to set up the information resource structure system which is the specialized, characteristic, systematized, refined, diversified and individualized integration to meet the needs of the readers. Fifth, according to the dynamic changes of readers' needs, we should timely adjust the structural framework.

\subsection{Speed up the development and utilization of information resources technology and facilities construction}

The deep development and utilization of information resources must rely on modern high technology, especially in the big data era, the existing network structure, data acquisition, storage, analysis and calculation of university libraries. It is more important to speed up the construction of technology and facilities for the development and utilization of information resources. First, it is necessary to accelerate the establishment of personalized service network structure adapted to Web 3.0; second, we should speed up the establishment of a distributed database for massive data storage that is rapidly increasing in the era of large data; at present, NOSQL system is widely used. Third, we should speed up the introduction and use of big data's advanced technology and equipment, such as Hadoop systems and cloud computing; fourth, it is necessary to speed up the introduction of intelligent management techniques and equipment, such as automatic book loan and return, intelligent inventory, automatic sorting, real-time navigation of book position and information, and so on.

\subsection{Building a team of librarians with scientific structure and high quality}

First, we should re-recognize the important role of librarians. In the age of big data, librarians are no longer simply the "goalkeeper" of the library and the "transfer man" of the literature information 
resources. The future library will focus on data management, and data management and service will become the librarian's main responsibility. Two we need to re-allocate and increase staffs. Under the new circumstances, the function of the university library and the demand of the reader have changed, and the content of the work will change. For example: digital processing of collection resources, development and utilization of network information resources, mining of library literature resources, integration and development of information resources, co-construction and sharing of information resources, data management, etc. These regular and systematic work must be completed by a special person. In order to ensure the service quality of the university library, we must rearrange the staff according to the actual situation, increase the staff establishment and ensure the scale of the librarian team.

\section{Conclusions}

Information resources, technical equipment and talents are the "three elements" in the construction of information resources in university libraries. In big data's time, the university library should grasp this point, grasp the information resources and the various behaviors of the readers to utilize the information resources, understand, analyze and excavate the hidden law of the information resources. We should make decisions on the construction of information resources, which can promote the construction of information resources closer to the needs of readers, and stand out in the face of the challenges of various media information resources so that to maintain the leading position of the university library in big data's time and to ensure the healthy and sustainable development of the university library.

\section{References}

[1] Li Zhen. The Research on Countermeasures of Era of Big Data in University Library Information Resources Construction [J]. University Library and Information Journal, 2017, (01):36 $-40$.

[2] Wu Wenxiu, Xu Lili, Li Xuzhen. Construction and Strategy of Information Resources in University Library under Big Data Environment [J]. Library and Information Guiding Journal11: 63-65.

[3] Duan Ruimei. Analysis on the Service Mode of University Library under Big Data Environment [J]. Library Work and Research. 2016, (09):107-109.

[4] Zhong Jieping. Construction and Service of Electronic Information Resources in University Library under Big Data Background [J]. Henan Library Journal, 2016 / 02: 53-55.

[5] Gao Yang. A Discussion on the Micro Service of the Digital Library Information Resources in the Big Data Era [J]. Vocational Education for Ships, 2015, (04):75 - 77.

[6] Han Xue. The Construction of University Library in Big Data Era [J]. Science and Technology Information, 2014, (8): 251.

[7] Kang Chunpeng, Du Rui. Opportunities and Challenges Brought by Big Data to the Library [J]. Modern Intelligence: 2014 / 05: 47-49 55. 